\title{
CLOTHING AND ACCESSORIES
}

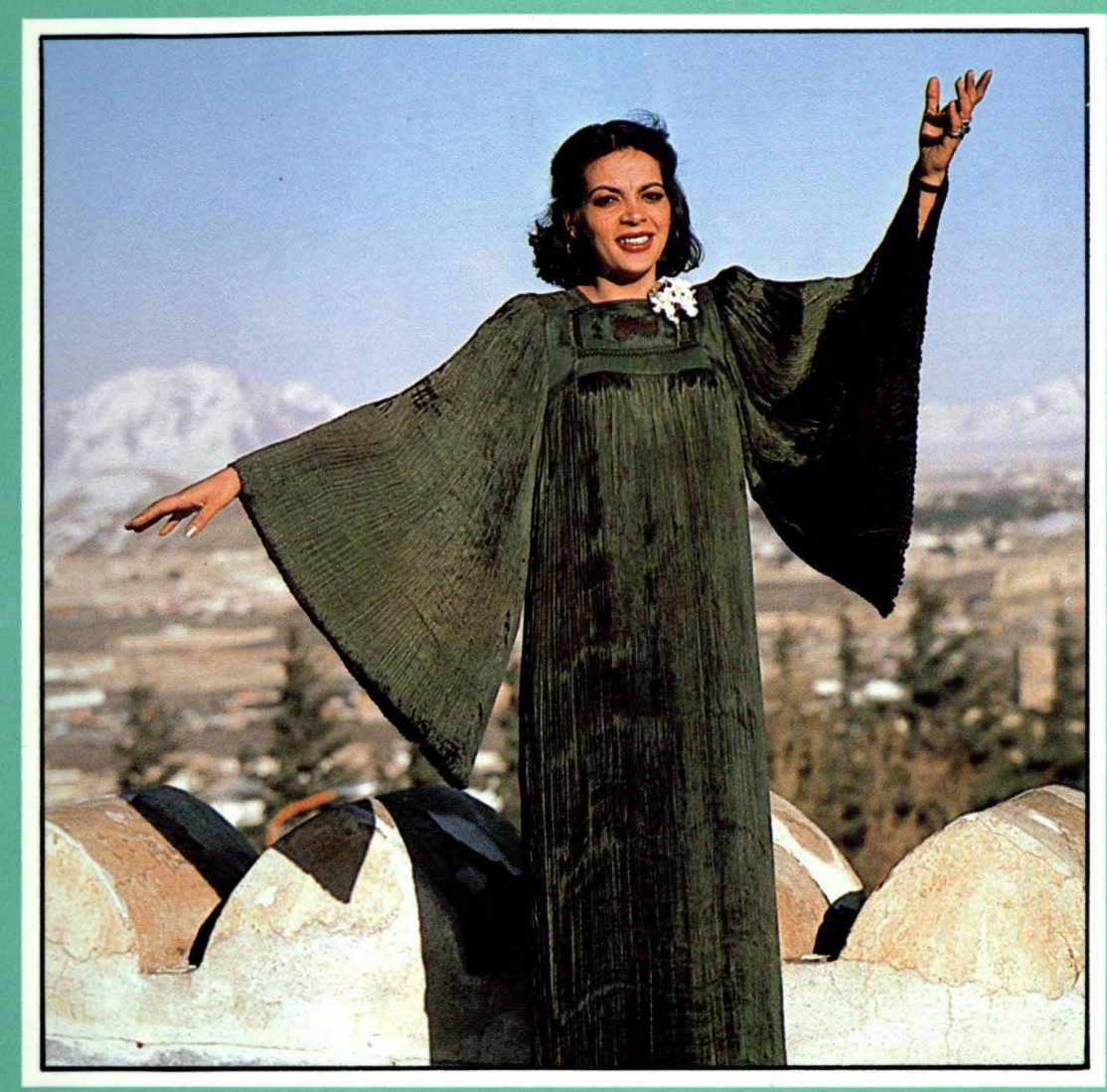

HANDMADE IN AFGHANISTAN 


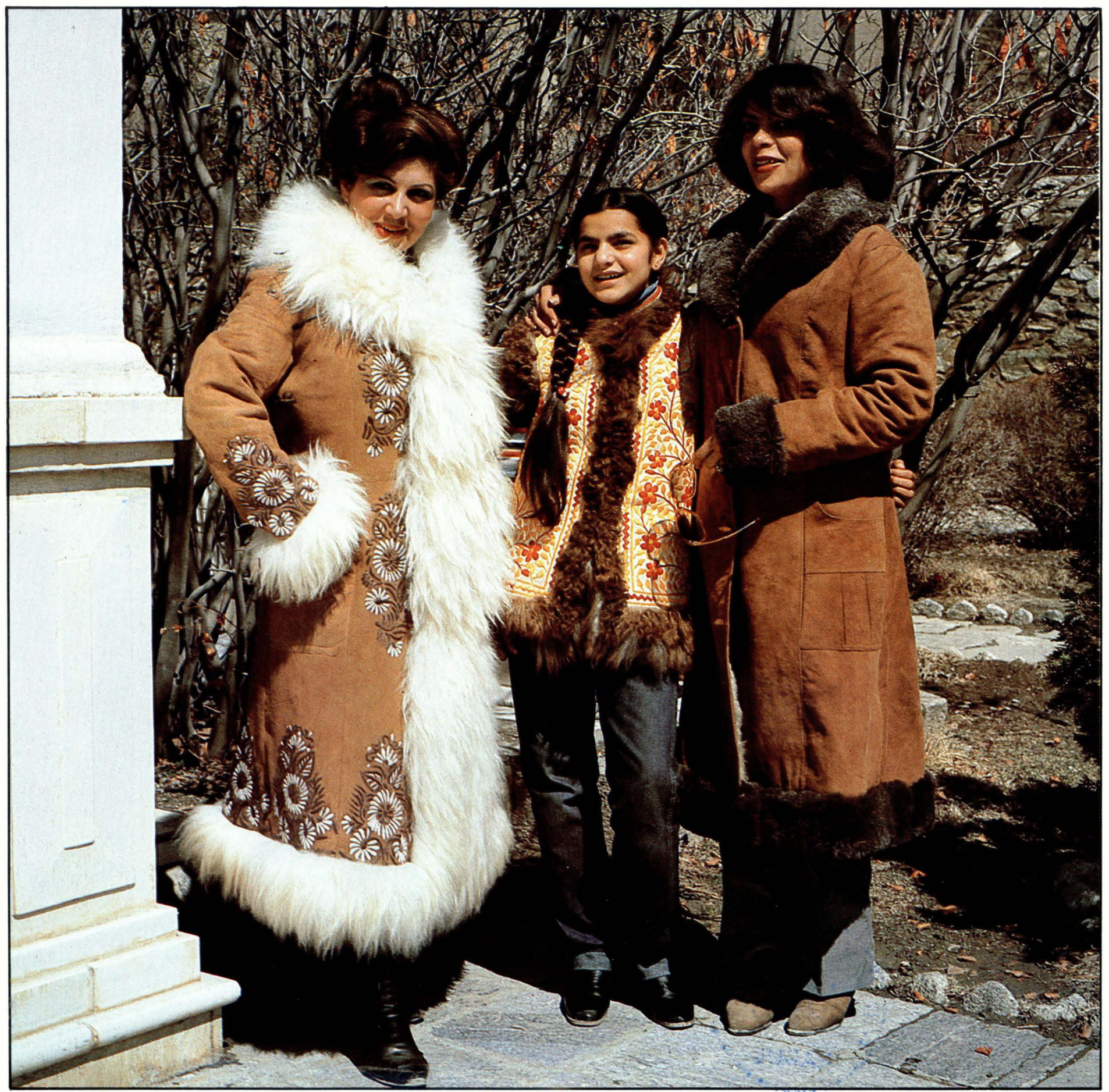


We export clothing and accessories, handmade in the villages of Afghanistan or in our own workshop. The materials include hand and machine loomed cottons, cotton/synthetic blends, hand-knitted pure mountain wool, and lambskin. The styling is varied; the look is distinctively Afghan.

We regularly produce new models. This brochure illustrate only a few of the many available. And we welcome orders to your own designs. Our company also exports jewelry featuring genuine lapis lazuli, leather goods and giftware.
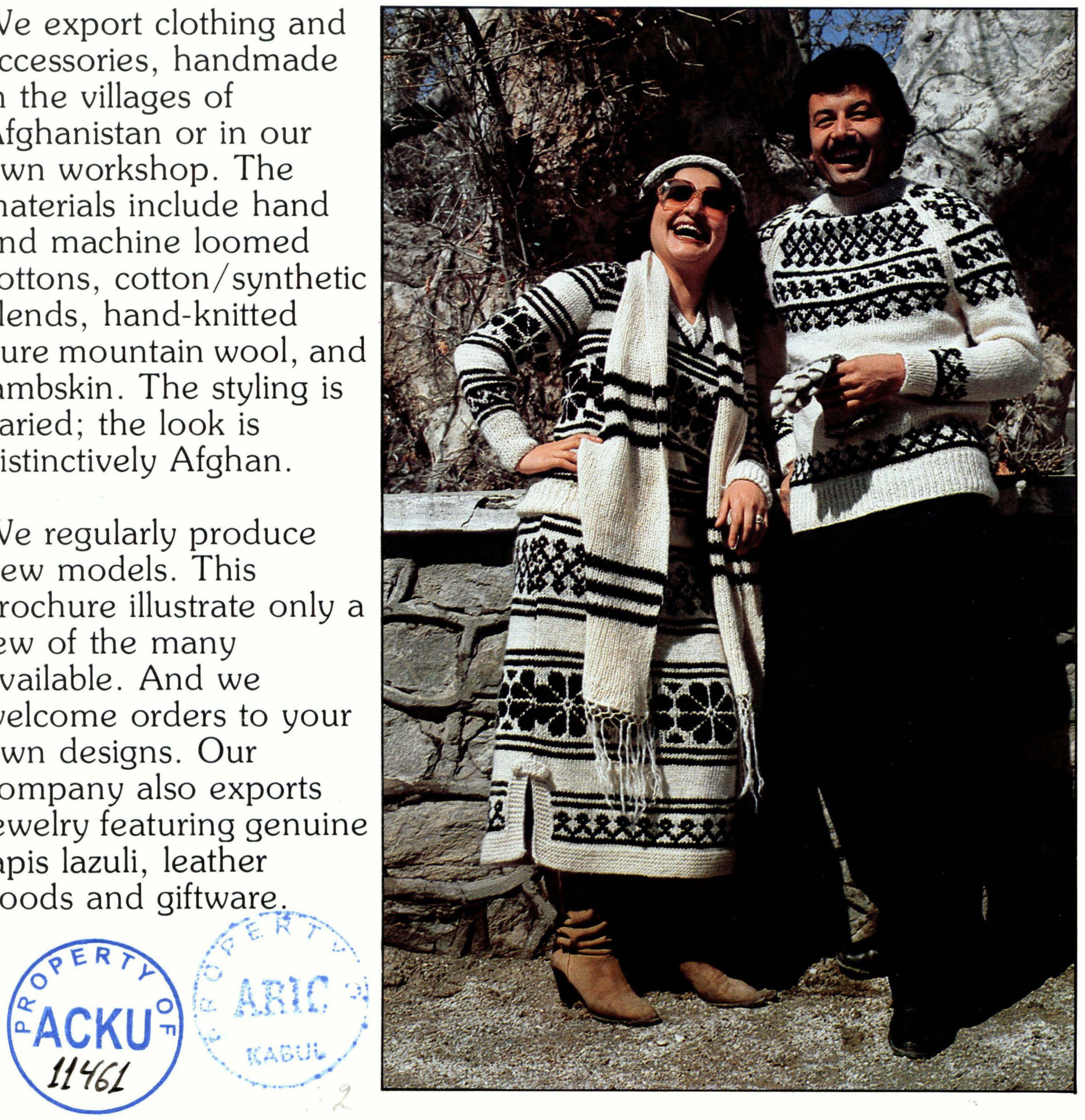


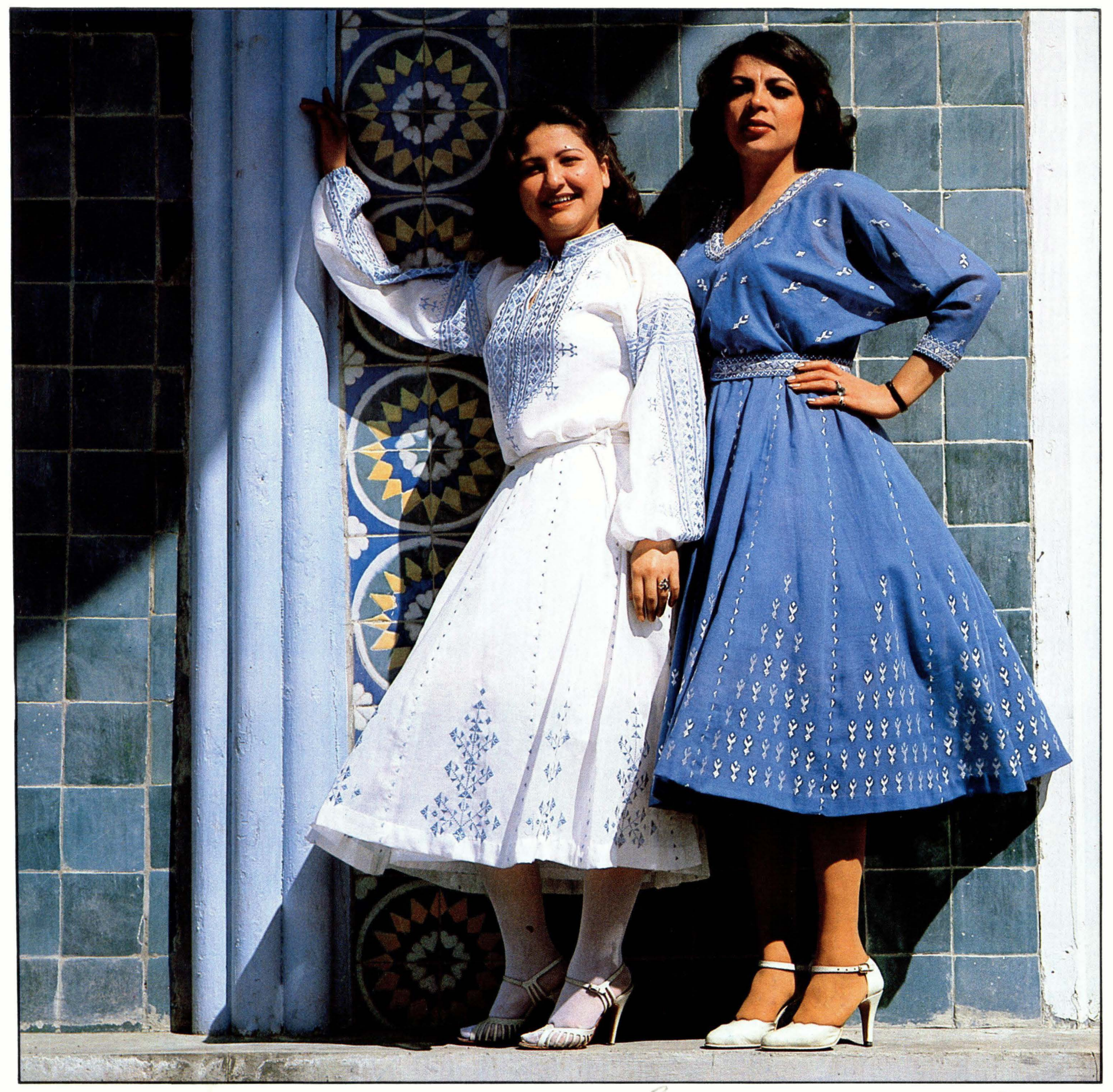




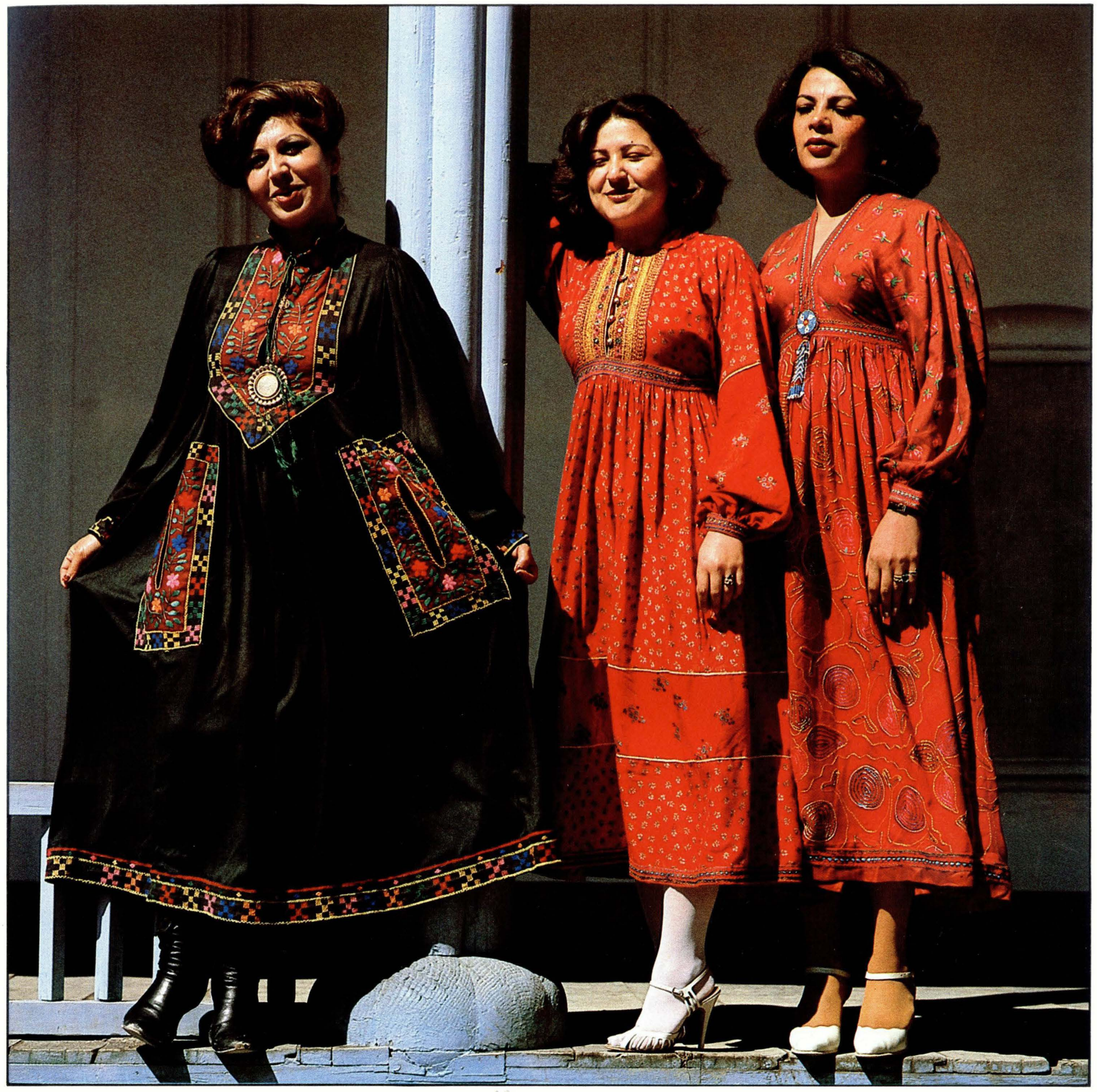




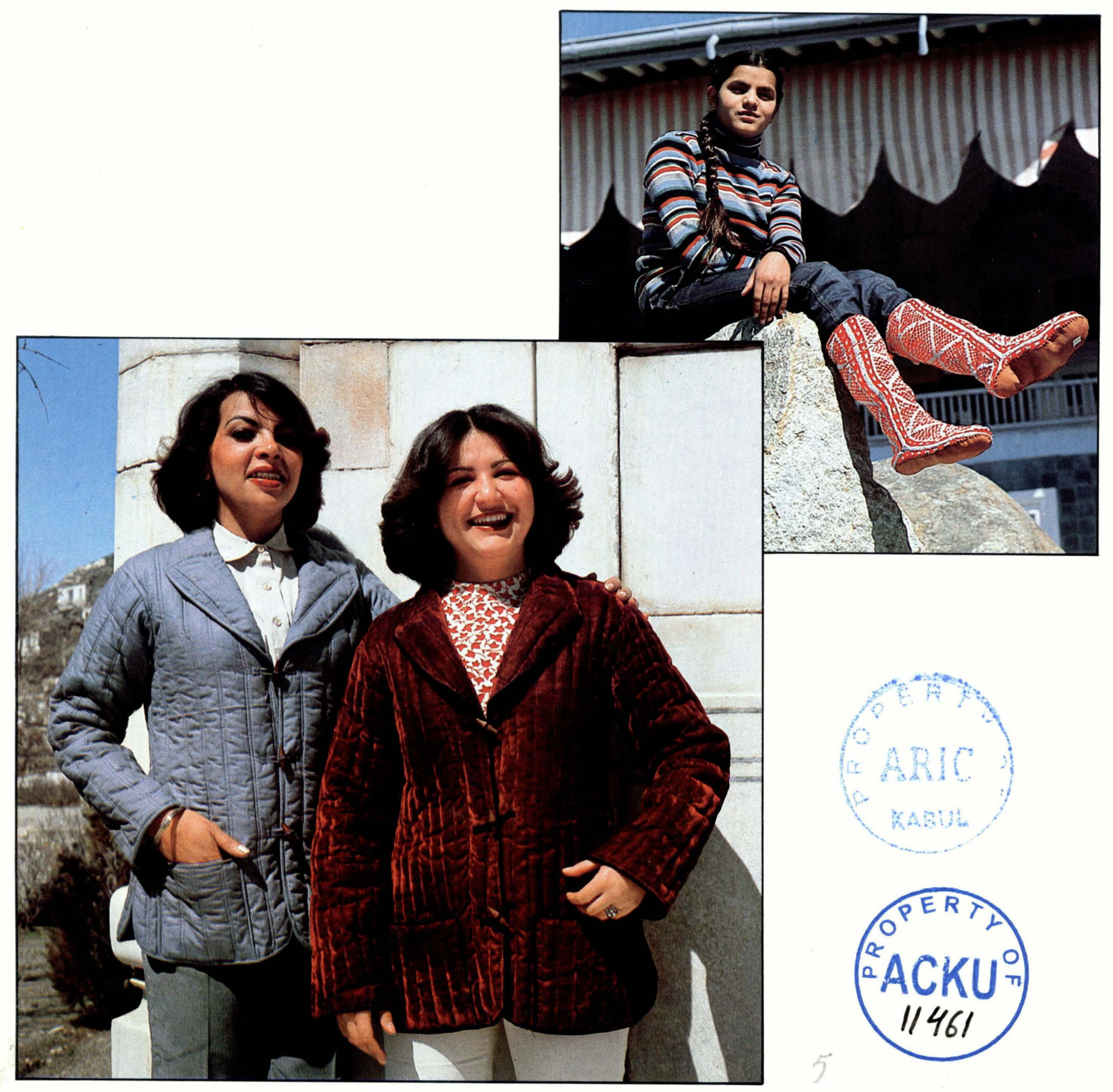




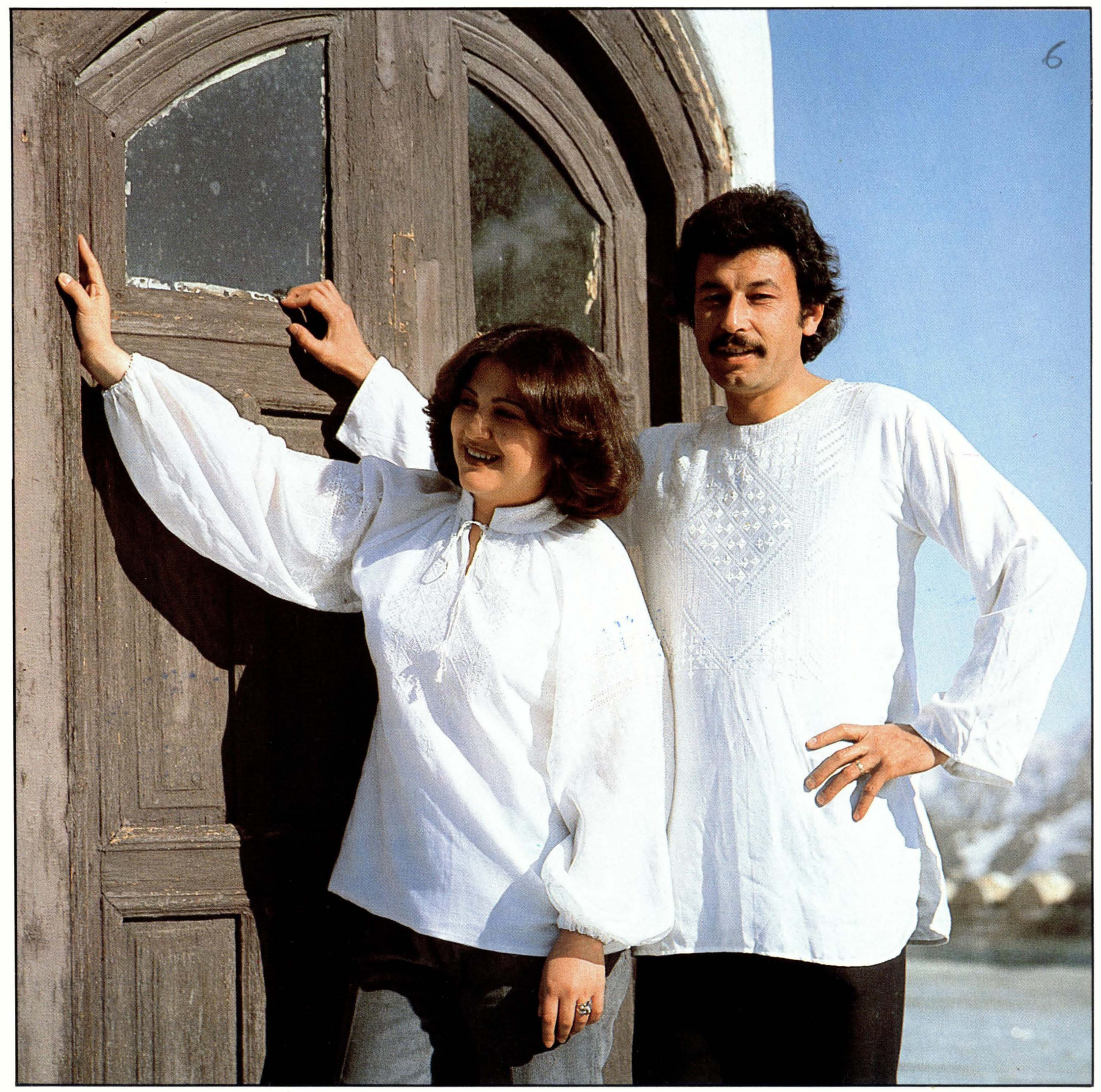


$A B D C$

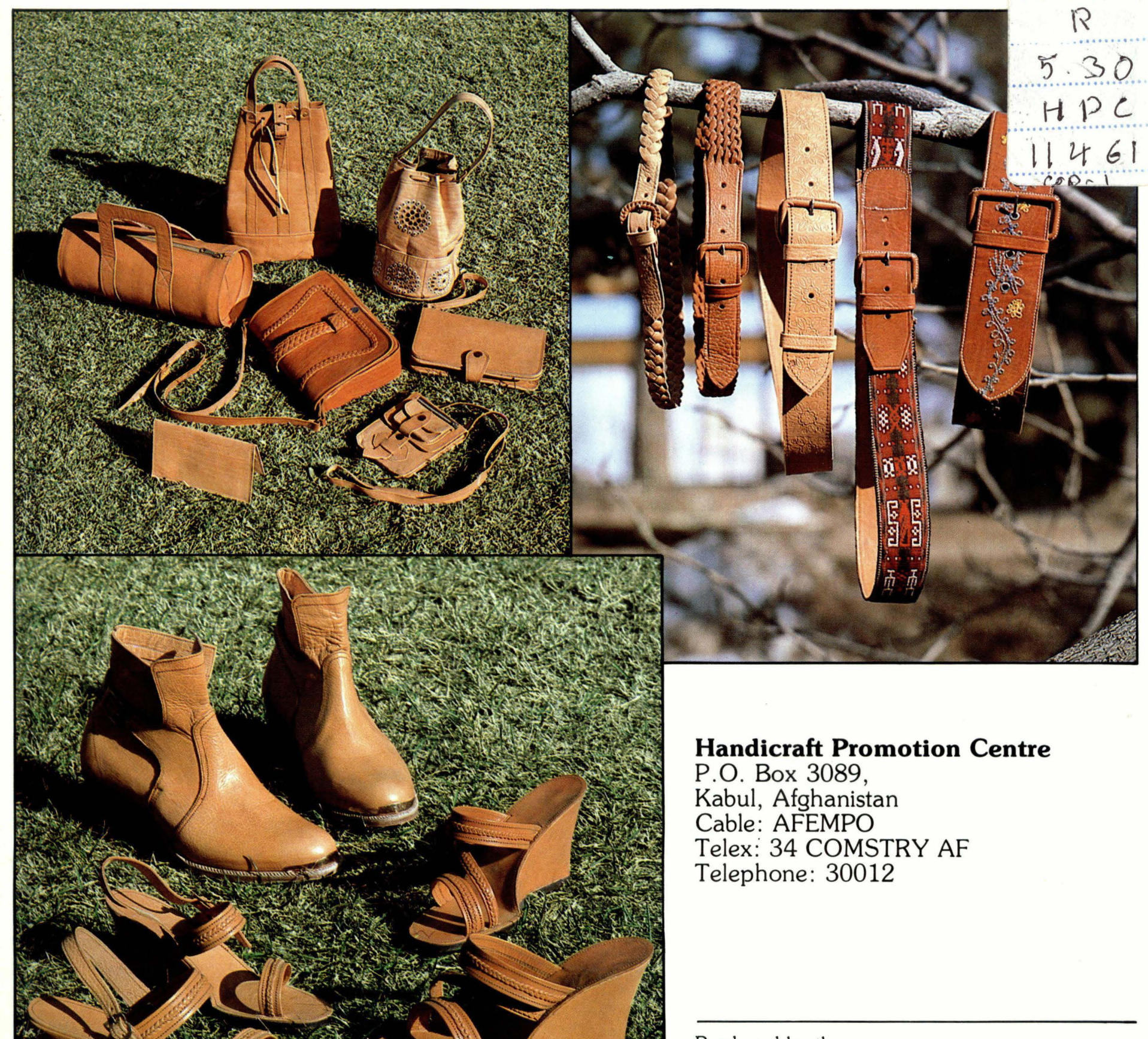

Produced by the

International Trade Centre UNCTAD/GATT. and financed by the

United Nations Development Programme 